\title{
Life Expectancy: Frequently Used, but Hardly Understood
}

\author{
Marc Luy ${ }^{a, b}$ Paola Di Giulio ${ }^{a, b}$ Vanessa Di Lego ${ }^{a, b}$ Patrick Lazareviča, \\ Markus Sauerberga, b \\ a Wittgenstein Centre for Demography and Global Human Capital (IIASA, VID/ÖAW, WU), Vienna, Austria; \\ b Vienna Institute of Demography, Austrian Academy of Sciences, Vienna, Austria
}

\section{Keywords}

Life expectancy $\cdot$ Cohort effects · Heterogeneity .

Harvesting effect $\cdot$ Tempo effects

\begin{abstract}
Period life expectancy is one of the most used summary indicators for the overall health of a population. Its levels and trends direct health policies, and researchers try to identify the determining risk factors to assess and forecast future developments. The use of period life expectancy is often based on the assumption that it directly reflects the mortality conditions of a certain year. Accordingly, the explanation for changes in life expectancy are typically sought in factors that have an immediate impact on current mortality conditions. It is frequently overlooked, however, that this indicator can also be affected by at least three kinds of effects, in particular in the situation of short-term fluctuations: cohort effects, heterogeneity effects, and tempo effects. We demonstrate their possible impact with the example of the almost Europe-wide decrease in life expectancy in 2015, which caused a series of reports about an upsurge of a health crisis, and we show that the consideration of these effects can lead to different conclusions. Therefore, we want to raise an awareness concerning the sensitivity of life expectancy to sudden changes and the menaces a misled interpretation of this indicator can cause.

(C) 2019 The Author(s)

Published by S. Karger AG, Basel
\end{abstract}

\section{KARGER}

E-Mail karger@karger.com www.karger.com/ger

Published by S. Karger AG, Basel

Open access

\section{C) 2019 The Author(s)}

Karger

This article is licensed under the Creative Commons AttributionNonCommercial-NoDerivatives 4.0 International License (CC BYNC-ND) (http://www.karger.com/Services/OpenAccessLicense). Usage and distribution for commercial purposes as well as any distribution of modified material requires written permission.

\section{Introduction}

Period life expectancy (PLE) is one of the most used summary indicators for the overall health of a population. It is based on the set of observed age-specific death rates, i.e., the number of deaths in a certain year and age group divided by the average number of people alive in this year and age group. These death rates are then transformed into probabilities of dying and connected to a survival function from birth to the highest age in which people are living. The mean age at death derived from this survival function is the PLE. It can be interpreted as the average number of years that newborns of a certain period would live under the hypothetical scenario that the prevailing age-specific death rates remain constant in the future [1].

The period perspective must be strictly distinguished from the cohort perspective. The latter is the more intuitive and more clearly interpretable analytic concept. It connects the age-specific death rates experienced by a cohort longitudinally over its entire life course. Thus, cohort life expectancy (CLE) reflects the actual mean age at death of real people who were born at the same time. Naturally, CLE can only summarize past mortality experiences, whereas PLE reflects the most current death rates cross-sectionally across all ages. This is why PLE is of higher relevance for most practical purposes and more frequently used than CLE.

Wittgenstein Centre for Demography and Global Human Capital (IIASA, VID/ÖAW, WU) Vienna Institute of Demography, Austrian Academy of Sciences

Welthandelsplatz 2, AT-1020 Vienna (Austria)

E-Mail mail@marcluy.eu 
Levels and trends of PLE direct health policies, and researchers try to identify the determining risk factors to assess and forecast future developments. Recently, most European populations experienced a decrease in PLE [2]. This surprising change led a number of newspaper articles to report this decrease as a signal of an alarming health crisis. Several experts supported this assessment with their comments and attempts to identify the cause of this phenomenon [3-7]. Consequently, future trends in PLE are now forecast more conservatively than they used to be, in particular regarding women for whom mortality statistics suggest a recent reduction in PLE improvements [8].

In this paper, we want to caution against misleading interpretations of changes in PLE that can arise due to the measurement's sensitivity to different factors. This is important because such interpretations may result in a premature identification of possible causes that drive those changes. The use of PLE is often based on the assumption that it directly reflects the "mortality conditions" of a certain year [9]. Accordingly, the explanation for changes in PLE are typically sought in factors that have an immediate impact on current mortality conditions. In accordance with Guillot [1], we refer to such factors as "period influences." The term "current mortality conditions" is frequently used in the interpretation of PLE but it lacks a clear definition. It can be described as a set of age-specific death rates that results from an underlying biological age pattern of human mortality under the impact of current period influences.

Note that period influences do not necessarily originate in the same year in which they affect mortality. This applies only to extreme external forces, such as wars, famines, natural disasters, epidemics, and exceptional cold and heat waves. ${ }^{1}$ Examples for period influences that take some time until they unfold their impact on mortality across a population include, e.g., improved hygiene and sanitation, new drugs and vaccinations, advanced medical technologies, or expansions in the availability of and access to medical care. Nonetheless, all these factors fulfill - at least approximately - the property that they would affect future death rates of newborns in the same way as they affect current death rates.

The difficulty in the interpretation of trends and changes in PLE roots in the circumstance that the death rates of a certain year are not only shaped by period influences. Additionally, they are affected by at least three kinds of effects which can bias the common period interpretation: cohort effects, heterogeneity effects, and tempo effects. The impacts of these effects on PLE can be significant, in particular regarding short-term fluctuations. Therefore, these possible biases should be taken into account to avoid misleading conclusions. In the subsequent sections we briefly summarize the main triggers and mechanisms behind cohort, heterogeneity, and tempo effects (an extensive illustration can be found in Guillot [1]). Then, we demonstrate how changes in PLE can be affected by these effects with the example of the 2015 decrease in PLE. Finally, we summarize the main conclusions and make suggestions for improving the use of PLE and reducing the possible bias in conclusions derived from this indicator.

\section{Cohort Effects}

Cohort effects originate from "health conditions that a cohort faces at a given time and that have a delayed impact on the cohort's mortality" [1, p. 536]. Such conditions include, e.g., exposure to infectious or noninfectious diseases, exposure to radiation during nuclear catastrophes, exposure to malnutrition during and after famines or wars, and health behaviors like diet, physical activity, alcohol consumption, or smoking. Cohort effects and their impact on mortality are extremely heterogeneous. As the given examples illustrate, they can change gradually over time, interact with each other, affect mortality over a broad range of ages, differ in the length of delay, and they can affect mortality both in the short as well as in the long run. Last but not least, the short- and long-term impacts may even operate in different directions. For instance, a more frequent exposure to diseases for which immunity can be acquired can generate high childhood mortality on the one hand, but low later life mortality from these diseases on the other [10].

In the period perspective, cohort effects appear as impacts on age-specific death rates several years or decades after they emerged. The decisive difference to delayed period influences is that they have an impact only on particular cohorts, but they do not have a general impact on specific age groups. Consequently, the mortality of newborns under the hypothetical current-condition scenario would not be affected equivalently by these effects once they reach today's age of the affected cohorts. ${ }^{2}$

\footnotetext{
Such immediate impacts on a population's mortality are often referred to as "period effects."

2 Note that a separation between period influences that originated earlier but unfold their impact on mortality in the observed period on the one hand and delayed cohort effects on the other is to some extent arbitrary. A clearcut allocation of some factors to the one group or the other is not possible (see also Guillot [1]).
}

Luy/Di Giulio/Di Lego/Lazarevič/ Sauerberg 
The above-mentioned features of cohort effects make their impact difficult to detect and even more difficult to quantify. One of such rare studies investigated the impact of past cohort smoking patterns on US period death rates of the year 2003 [11]. The authors compared the survival according to the period life table of that year (including the impact of actual smoking histories) with the predicted survival on the basis of current age-specific smoking prevalence. They estimated that the probability to survive from age 50 to 85 under current smoking behavior would be 0.38 for men and 0.48 for women, whereas the US life table provided values of 0.30 and 0.46 , respectively. The difference between the predicted and actual survival probabilities reflects the impact of smoking-specific cohort effects on period death rates which results in an overestimation of mortality (and thus an underestimation of PLE) under the scenario of constant current conditions. Given that smoking spreads in a population like an epidemic with a 20 - to 30 -year delay between men and women [12], it seems likely that the recent decrease in female PLE improvements is - at least to some extent - due to the delayed effect of past cohort smoking patterns [13].

\section{Heterogeneity Effects}

Heterogeneity describes the circumstance that not all members of a population face the same risk of dying in a certain year and age. The characteristics that shape individuals' mortality risks may be fixed at birth or at a young age (e.g., ethnicity or education) or they may vary with age (e.g., health status or income). The composition of the total population of low-risk and high-risk individuals would be no problem if it were constant over time and across populations. This is not the case, however, and the impacts on PLE can be significant. ${ }^{3}$ For instance, Luy et al. [14] estimated for several western countries that between 15 and $40 \%$ of the increases in PLE during the last few decades can be attributed to the changing composition of the populations by level of education, independently of the effect of decreased death rates. Other studies arrived at even larger impacts of such structural changes for nonwestern populations $[15,16]$.

In addition to such structural effects of heterogeneity, the different mortality risks of individuals lead to "selection effects" [17]. These are closely related to cohort effects

\footnotetext{
3 The construction of a survival function in the period perspective ignores a population's heterogeneity as it treats all newborns as a group of homogeneous individuals with identical mortality risks.
}

Life Expectancy: Frequently Used, but Hardly Understood as they also develop their impact on age-specific death rates along the cohorts' life courses. For characteristics that are fixed once they are experienced, the proportion of individuals possessing characteristics associated with higher mortality decreases over time, while the proportion of those who possess characteristics with lower mortality increases. A disproportionate fraction of robust survivors can also be caused by strong period influences, such as high levels of infant and child mortality or wars. For instance, some studies provided evidence that the opening of the gender gap in PLE in West Germany during the 1960s and 1970s was caused in particular by those cohorts who were at childhood or young adult ages during the two world wars, suggesting that - beside the above-mentioned effect of smoking - different selection mechanisms among women and men unfolded their delayed effects on female and male mortality once these cohorts reached the age in which heart diseases become the major cause of death $[18,19]$.

A special case of selection is the so-called "harvesting effect," also referred to as "mortality displacement," which describes a short-term impact of sudden variations in a population's risk pool on overall mortality, mainly related to the phenomenon of anticipated deaths caused by heat waves or cold spells [20,21]. The selective mortality among the frailest individuals increases the number of deaths in the total population during the impact of these exogenous events but leaves a large proportion of robust survivors which leads - as "late-harvesting" effect - to a lower than expected number of deaths for some time thereafter [2224]. The short-term mortality fluctuations caused by these mechanisms become apparent when one considers the relationship between milder or harsher winters (regarding temperature and/or flu waves) and subsequent summers. Studies have shown that winters with high mortality led to a delayed and reduced effect of the subsequent summer heat wave compared to winters with low mortality $[25,26]$.

\section{Tempo Effects}

Tempo effects (TE) were identified only quite recently as potential bias of PLE's typical interpretation to reflect current mortality conditions [27]. In contrast to the causal influences on PLE described in the previous sections, TE are a methodological artifact which occurs because the conceptual assumptions behind the indicator are violated in real populations. Most scholars are aware that the PLE indicator is derived from the theoretical model of the stable population. It is often overlooked, however, that the requirements to apply this model to a real population are 
not sufficiently satisfied with the hypothetical scenario that the actually observed period death rates remain constant in the future. The stable population model assumes that the death rates are always constant, including the observation period itself. This assumption is not fulfilled when PLE varies between calendar years.

In brief, TE emerge in death rates as soon as mortality is changing during the observation period. For example, when improvements in health and living conditions lead to a reduction in mortality, a certain number of deaths which would have occurred under unchanged mortality conditions - are postponed to a later period. Such a postponement consequentially deflates the numerator of death rates by the number of avoided deaths, while the denominator is inflated by the same number of saved lives. Albeit these numbers are identical in absolute terms, they differ notably in relative terms. The number of deaths decreases by a much larger proportion than the number of the population at risk in the denominator increases. In this way, TE magnify the effect of the shifted number of deaths in the death rate. The larger the changes in mortality, the larger the magnification effect.

As long as these magnification effects are of minor extent, the conclusions derived from an analysis of PLE might not be affected. However, model simulations which provide easily comprehensible illustrations of the tempo bias in death rates - have shown that TE can lead to paradoxical situations when their extent differs strongly between the compared populations or periods [28-30]. For instance, it is possible that period death rates increase despite all cohorts living in this period are experiencing only decreasing or stalling mortality $[27,31]$. Thus, TE can be a highly relevant factor for explaining trends and differentials in PLE in situations of marked changes in mortality dynamics. It has been shown, for instance, that TE caused by the sudden decrease in mortality in eastern Germany after unification are likely to be a significant contributor to the unexpectedly rapid convergence of eastern Germany's PLE to the level of western Germany $[32,33]$.

\section{The 2015 Decrease in Life Expectancy}

The sudden and surprising decrease in PLE in the year 2015 led to a number of speculations about its causes. However, despite the intensive effort of researchers, no specific factor has been identified which caused more than only a fraction of the decrease in PLE. The first reports and scientific publications about this phenomenon focused exclusively on country-specific explanations, such as a flu vaccination crisis in Italy $[3,34]$ and cuts in the health and social care system in England and Wales $[5,35]$. It was overlooked for a long time and recognized only in the most recent discussions that the decrease in PLE occurred simultaneously in almost all countries of Europe, which speaks against the exclusive effect of country-specific factors. ${ }^{4}$ The only discussed factors that could provide an explanation for this wide geographical phenomenon are a strong flu wave in early $2015[39,40]$ and an exceptional heat wave in the summer of 2015 [41, 42]. Yet, empirical estimates of these effects also explained only parts of the decrease in PLE, whereas the majority of the lost life years remained unexplained [37].

As it is the case for all phenomena of demographic differences and variations, the reason for changes in PLE is unlikely to be found in one single factor. However, the main problem lies in the fact that all the above-mentioned attempts to identify the cause for the decrease in PLE in 2015 are based on the expectation that the primary explanation must be found in specific period influences. In the following, we demonstrate how in particular harvesting and tempo effects might have significantly contributed to the PLE decrease in 2015. Their interaction with the other single factors might not only help to bridge the gap of the unexplained fraction of the PLE decrease. As we will show, an explanation including these effects will also lead to a different interpretation of the most recent changes in PLE. ${ }^{5}$

Basically, all discussions so far concentrated exclusively on the lower PLE in 2015 compared to 2014. What has been overlooked is that the much more marked change occurred between 2013 and 2014 with an exceptional increase in PLE (also Raleigh [44] mentioned this observation in a recent $B M J$ editorial). Figure 1 shows the trends in female PLE in Belgium, France, the Netherlands, and the UK in black lines with the values relating to the left

\footnotetext{
4 The first and most prominent reports about the 2015 mortality crisis referred to the USA, where the decrease in LE was related in particular to the increasing number of deaths caused by the consumption of opioids [36, 37]. Albeit the explanation we suggest for the 2015 decrease in PLE applies to the USA as well, we restrict our analysis to European populations for the following reason. In contrast to the European populations, the USA experienced a further decrease or stall in PLE also in the years after 2015. This indicates the prevalence of additional influences on mortality, most likely connected to increasing mortality among particular disadvantaged subpopulations of low social status, whose excess in mortality is generally larger than in western European populations [38].

A third component - which we do not explain in detail in this paper - can be seen in the recent general decreasing pace of PLE improvement, in particular among women [43]. This trend change is also relevant for the interpretation of the year 2015 because it becomes more likely that the usual annual fluctuations in PLE lead more frequently to short-term decreases which would have not occurred in times of stronger paces of PLE improvement (see also Le Bourg [8]).
}

Luy/Di Giulio/Di Lego/Lazarevič/ Sauerberg 
$y$ axis. ${ }^{6}$ The graphs elucidate the connection between the PLE decrease in 2015 and the PLE increase in 2014. This is an important observation because it suggests that the decrease in PLE in 2015 results primarily from the exceptional high survival in 2014, and not - at least not as much - from a mortality crisis in $2015 .{ }^{7}$

The low mortality in 2014 - which can be primarily attributed to an unusual mild influenza type during the winter 2013/14 [45] - has two important consequences for the period death rates in 2014 and 2015. First, an exceptionally low mortality leads to an exceptionally high number of survivors. This increase in survivors - and the consequential reduction of deaths - decreases not only the death rates of the year with low mortality. As explained in the section on heterogeneity effects, a year with exceptionally low mortality increases the pool of potential deaths in the next year(s), above all because these exceptional survivors include a high proportion of frail survivors [see also 46]. These have an increased likelihood of dying when mortality conditions become "normal" again, in particular if this happens jointly with a stronger influenza-dominant type as it occurred in $2015[39,47,48]$. The second consequence of the shift of deaths from 2014 to 2015 is the emergence of TE which boost the effects of factual mortality changes on PLE in both years, the increase in 2014 and the decrease in 2015.

A useful - but only rarely used - demographic indicator to demonstrate these changes in mortality dynamics is the total mortality rate (TMR) because it quantifies the amount of shifted deaths (delayed or speeded up) in a period. The TMR represents the cross-sectional sum of cohort deaths in a particular calendar year standardized for the size of cohorts (i.e., death rates of "second kind") and equals 1.0 when mortality remains unchanged during the year of observation. ${ }^{8}$ As soon as some or all currently living cohorts experience a change in mortality (i.e., a shift in deaths to earlier or later calendar years), the TMR leaves unity and becomes higher than 1.0 in the case of increasing mortality and lower than 1.0 in the case of decreasing mortality [50]. What makes the TMR particularly interesting is that it deviates from 1.0 by the proportion of deaths that are shifted out of or into the period of observation, relative to the hypothetical situation of constant mortality (for details, see Guillot [51]).

To estimate the TMR we reconstructed the complete longitudinal survival for each cohort alive during the years 2009-2015 from the age-specific death rates retrieved from the Human Mortality Database [52]. We then determined the cohort-specific proportion of deaths occurring in these calendar years and derived the TMR for each year by summing up the corresponding proportions across all cohorts.
The graphs in Figure 1 include the TMR trends with gray dotted lines referring to the $y$ axes on the right-hand side. A look at the decisive years 2013-2015 reveals for all populations that the strong increase in PLE in 2014 coincides with a strong decrease of the TMR, illustrating the impact of an exceptional number of deaths being shifted from 2014 into the next year(s). Likewise, the decrease in PLE in 2015 coincides with a corresponding increase of the TMR. ${ }^{9}$

Finally, we tested the possible impact of TE caused by the shift of deaths by comparing the trends in conventional PLE with three alternative measures for period longevity which are unbiased by TE: Bongaarts and Feeney's tempo-adjusted life expectancy (LE*), the "cross-sectional average length of life" (CAL), and the "mean age at death" (MAD) (a description of the indicators' features and estimation methods can be found in Bongaarts [53]). ${ }^{10}$ The results shown in Figure 2 reveal the strong

6 The figures refer to PLE at the age of 30 to keep consistency throughout the paper. All other indicators shown in Figures 1 and 2 exclude ages below 30 for technical reasons or because of limitations in data availability. Nonetheless, the figures for PLE at the age of 30 do not differ from those for PLE at birth [2]. This holds equivalently for the other indicators as far as these could be estimated from birth with the available data.

The corresponding figures for men are not shown because they are basically identical to those for women.

8 Death rates of "second kind" relate the number of deaths experienced by the members of a cohort in a particular year to all ever-born members of this cohort, i.e. those who are still alive as well as those who have already died. Agespecific death rates of a period, i.e. the basis of PLE, are death rates of "first kind" which are also called "hazards" or "occurrence-exposure rates." The denominator of rates of first kind includes all individuals living in a specific year, thus only the persons at risk of experiencing death during the observation period. Death rates of second kind, by contrast, do not reflect the mortality of a period in the sense of deaths per person (year), they reflect the proportion of cohort deaths which occur in this period. In contrast to death rates of first kind, rates of second kind are free of tempo distortions because the tempo distortion occurs in both the numerator and the denominator of the rates, and thus cancels out (for details, see Bongaarts and Feeney [49]).

9 Note that the situation is somewhat different for the UK compared to the other three European populations because the UK experienced a smaller increase in PLE in 2014 and a stronger decrease in PLE in 2015. Nonetheless, we find a similar correspondence of decreasing/increasing TMR and increasing/ decreasing PLE in 2014 and 2015.

10 Four different methods have been developed to estimate tempo-adjusted LE* [54]. These methods are, however, only variants for performing mortality tempo adjustment and arrive essentially at the same estimates [30]. We used the TMR method because it utilizes the property of the TMR to directly reflect the level of TE in a particular period. The agespecific death rates were thus adjusted by division with the corresponding annual TMR values. It should be noted, however, that all four methods for estimating LE* imply that the schedule of age-specific death rates shifts proportionally across all ages. This assumption is violated during the changes between 2014 and 2015. In some age groups, death rates increased in 2015 compared to 2014, in other age groups they decreased. Nonetheless, we performed test simulations which revealed that the estimations are not affected by the constant shape assumption of the Bongaarts-Feeney-model. The $\mathrm{R}$ codes for all calculations carried out for this paper are available at https://github.com/msauerberg/Gerontology_2019. 


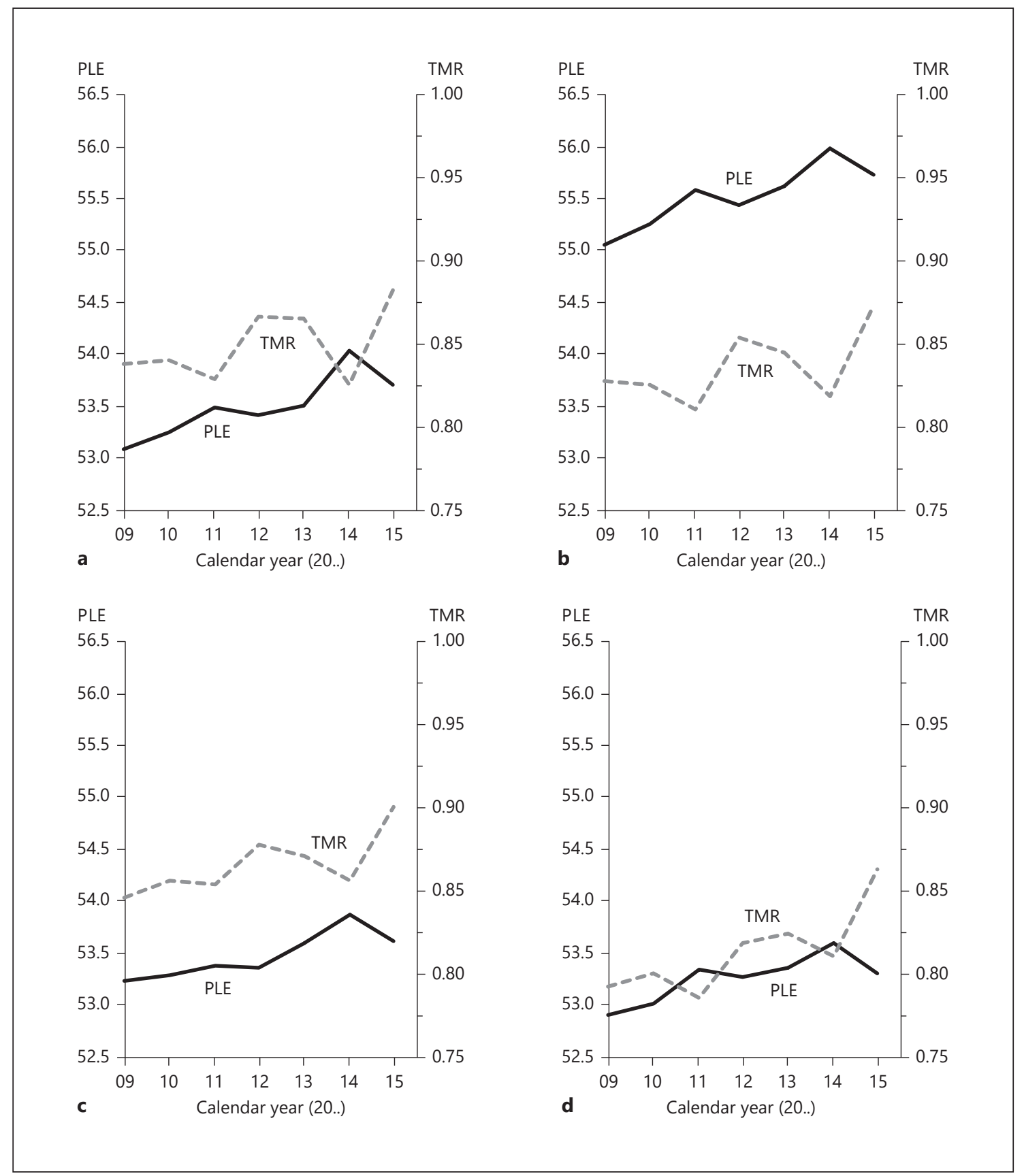

Fig. 1. Trends in period life expectancy (PLE, left $y$ axes) and the total mortality rate (TMR, right $y$ axes) in selected countries, women, 2009-2015. a Belgium. b France. c The Netherlands. d UK.

potential contribution of TE to the decrease in PLE in all four populations: LE*, CAL, and MAD continued to increase in 2015 without marked fluctuations. Thus, once $\mathrm{TE}$ are taken into account, we find no indication of a health crisis that has affected the mortality conditions of the total populations. This is even more evident by the fact that the TMR for the year 2015 lies below 1.0 in all populations (Fig. 1). This indicates that even in the year of declining PLE, mortality has still been decreasing rather than increasing among the currently living cohorts. 


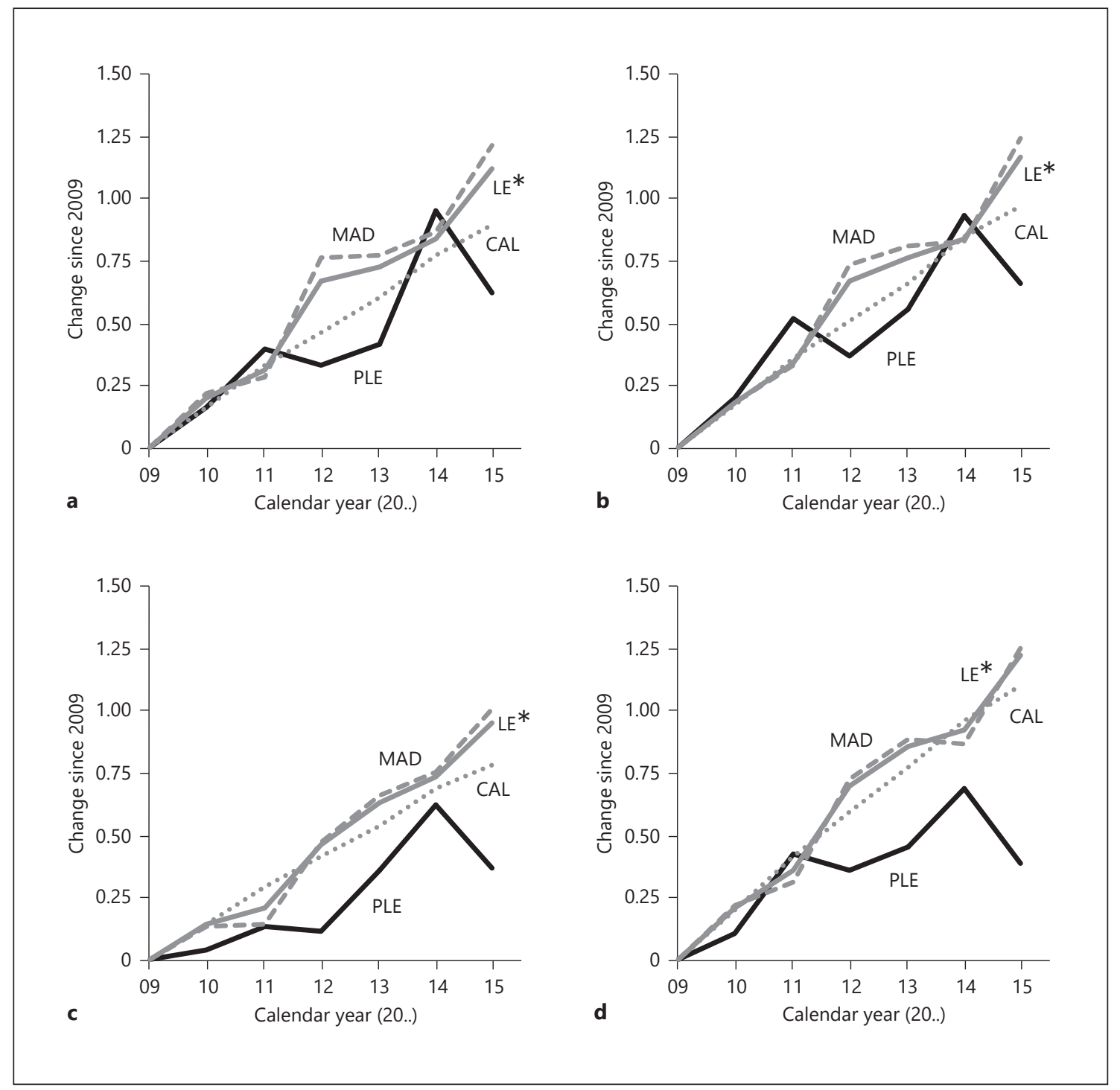

Fig. 2. Changes in period life expectancy (PLE), tempo-adjusted life expectancy (LE*), cross-sectional average length of life (CAL), and mean age at death (MAD) relative to 2009 in selected countries, women, 2009-2015. a Belgium. b France. c The Netherlands. d UK.

\section{Summary and Conclusion}

The aim of this paper is to raise awareness that changes in PLE can be caused by complex mechanisms. The most common practical usages of this indicator include two main sources for potential misinterpretations. First, it is often overlooked that PLE reflects the mortality of a purely hypothetical population. The interpretation as reflection of current mortality conditions of the real population can lead to biased conclusions in particular when PLE varies markedly between years. This becomes prob- lematic in combination with the second frequent assumption that PLE is independent from previous periods and reflects exclusively the current mortality conditions. Consequently, it is typically assumed that increases or decreases in PLE directly reflect an improvement or deterioration of the population's mortality conditions, respectively. However, mortality conditions in a particular year are not independent from earlier periods with regard to both, causal mechanism and - what is often overlooked - technical characteristics of the indicator. The joint impacts of period influences, cohort effects, heterogeneity 
effects and TE, with each of them being complex themselves, make it very difficult to put all pieces of the puzzle together to a complete, overall picture.

We demonstrated the possible impact of these effects with the example of the almost Europe-wide decrease in PLE in the year 2015. The results of our conceptual considerations and empirical analyses can be summarized as follows:

1 The 2015 decrease in PLE occurred simultaneously in the majority of European countries. This suggests no exclusive effect of country-specific factors on which most of the corresponding publications focused. These might have contributed to an increase in mortality in 2015 , but obviously there were significant mechanisms at play which exceed the borders of single countries.

2 The decrease in PLE between 2014 and 2015 primarily occurred because of an exceptionally low mortality in 2014 and less because of an exceptionally high mortality in 2015. The missing recognition of this connection is a consequence of the widespread expectation that PLE are independent of each other.

3 The exceptionally low mortality in 2014 led to an increased number of survivors compared to "normal" conditions. Naturally, a certain proportion of these survivors can be considered frail survivors. Thus, many of these additional survivors died in 2015, increasing the number of deaths and resulting in increased death rates and a decrease in PLE (late-harvesting effect). Different influenza types in the winter months are likely a driving force behind these fluctuations, with a mild influenza type in 2013/2014 followed by a strong one in 2014/2015.

4 The shift of deaths created TE which caused an inflated decrease in death rates in 2014 and an inflated increase in death rates in 2015 , thus boosting the difference in PLE between the 2 years. The empirical results for trends in $\mathrm{LE}^{*}, \mathrm{CAL}$, and MAD indicate that the bias caused by TE might be even the primary factor which caused the picture of worsening mortality conditions. The consideration of harvesting effects and TE turns the interpretation of the 2015 decrease in PLE in a very different direction: instead of being seen as an indicator for very unfavorable mortality conditions in 2015, it becomes a partly causal and partly methodological consequence of very favorable mortality conditions in 2014. Thus, taking into account the potential impact of other factors than only period influences leads to the conclu-

\footnotetext{
11 Naturally, this holds likewise for the opioid crisis in the USA (see footnote 4).
}

sion that the 2015 decrease in PLE might not be a matter of big concern regarding the total population level. It is important to note, however, that this does not mean that there is nothing to worry about. Conditions like the health care crisis in the UK or the flu vaccination crisis in Italy are important issues for many individuals and specific subpopulations, and it is very important to fight these crises. ${ }^{11}$ Nonetheless, it is unlikely that these factors caused the decrease in PLE of the total populations.

The most evident support for our conclusion comes from the fact that no specific factor could be identified so far that explains more than a fraction of the PLE decrease in 2015. The supposed causes seem convincing at first glance, but none of them was supported with empirical data. Decomposition analyses of changes in PLE by age and cause of death did not lead to conclusive results either [37, 39]. Further, it is important to note that the decrease in PLE seems to be primarily an effect of only a single year. Between 2015 and 2016, PLE increased again in all of the European countries which experienced a decrease between 2014 and 2015, in many cases even to a higher level than in 2014 [2].

To conclude, PLE is one of the most used indicators for the overall health of a population, but it is rarely understood in all its features. While it is useful and intuitive because it expresses mortality conditions in terms of life years, it is important to take all mechanisms into account that might influence its values when changes between years or populations are analyzed. PLE is sensitive to biases, in particular in situations of strong fluctuations and trend changes. In such cases, we recommend to consider additional alternative indicators for period mortality before interpreting changes in PLE. This practice is routinely used in the analysis of fertility where no thorough study interprets changes in the total fertility rate without including at least trends in the mean age at childbearing and, whenever possible, using also alternative indicators for the average number of children [55]. Possible indicators for the analysis of period mortality are the TMR which illustrates the amount of shifted deaths between the periods, and LE*, CAL, or MAD which are based on different concepts than conventional PLE but are not biased by TE. PLE as a summary indicator for population health is too relevant for health policies and public health measures to risk potentially misleading interpretations.

\section{Acknowledgment}

This project has received funding from the European Research Council under the EU's Horizon 2020 Research and Innovation Programme, Grant Agreement No. 725187 (LETHE).
Luy/Di Giulio/Di Lego/Lazarevič/ Sauerberg 


\section{References}

1 Guillot M. Period versus cohort life expectancy. In: Rogers RG, Crimmins EM, editors. International handbook of adult mortality. Dordrecht: Springer; 2011. p. 533-50.

2 Eurostat: Life expectancy at birth by sex [cited 2019 Feb 4]. Available from: https://ec.europa.eu/eurostat/tgm/table.do?tab=table\&init= 1 \&language $=$ en $\&$ pcode $=$ sdg_03_10\&plug in $=1$

3 Francia F, Pandolfi P, Odone A, Signorelli C. Excess mortality in Italy: should we care about low influenza vaccine uptake? Scand J Public Health. 2018 Mar;46(2):170-4

4 Green MA, Dorling D, Minton J, Pickett KE. Could the rise in mortality rates since 2015 be explained by changes in the number of delayed discharges of NHS patients? J Epidemiol Community Health. 2017 Nov;71(11): 1068-71.

5 Hiam L, Dorling D, Harrison D, McKee M. What caused the spike in mortality in England and Wales in January 2015? J R Soc Med. 2017 Apr;110(4):131-7.

6 Hiam L, Dorling D, McKee M. Rise in mortality - when will the government take note? BMJ. 2018 Jun;361:k2747.

7 Signorelli C, Odone A. Dramatic 2015 excess mortality in Italy: a $9.1 \%$ increase that needs to be explained. Scand J Public Health. 2016 Aug;44(6):549-50.

8 Le Bourg E. Is life expectancy of French women going to plateau and oscillate? Gerontology. 2019;65(3):288-93.

9 Vaupel JW. Life expectancy at current rates vs. current conditions: a reflexion stimulated by Bongaarts and Feeney's 'How long do we live?' Demogr Res. 2002;7:365-78.

10 Preston SH, Hill ME, Drevenstedt GL. Childhood conditions that predict survival to advanced ages among African-Americans. Soc Sci Med. 1998 Nov;47(9):1231-46.

11 Preston SH, Wang H. Sex mortality differences in the United States: the role of cohort smoking patterns. Demography. 2006 Nov; 43(4):631-46.

12 Lopez AD, Collishaw NE, Piha T. A descriptive model of the cigarette epidemic in developed countries. Tob Control. 1994;3(3): 242-7.

13 Lindahl-Jacobsen R, Rau R, Jeune B, Canudas-Romo V, Lenart A, Christensen K, et al. Rise, stagnation, and rise of Danish women's life expectancy. Proc Natl Acad Sci USA. 2016 Apr;113(15):4015-20.

14 Luy $M$, Zannella $M$, Wegner-Siegmundt C, Minagawa Y, Lutz W, Caselli G. The impact of increasing education levels on rising life expectancy: a decomposition analysis for Italy, Denmark, and the USA. Genus. 2019;75(1):11

15 Shkolnikov VM, Andreev EM, Jasilionis D, Leinsalu M, Antonova OI, McKee M. The changing relation between education and life expectancy in central and eastern Europe in the 1990s. J Epidemiol Community Health. 2006 Oct; 60(10):875-81.
16 Turra CM, Renteria E, Guimarães R. The effect of changes in educational composition on adult female mortality in Brazil. Res Aging. 2016 Apr;38(3):283-98.

17 Vaupel JW, Manton KG, Stallard E. The impact of heterogeneity in individual frailty on the dynamics of mortality. Demography. 1979 Aug;16(3):439-54.

18 Horiuchi S. The long-term impact of war on mortality: old-age mortality of the First World War survivors in the Federal Republic of Germany. Popul Bull UN. 1983;15(15):8092.

19 Luy M, Zielonke N. Die geschlechtsspezifischen Sterblichkeitsunterschiede in West- und Ostdeutschland unter besonderer Berücksichtigung der kriegsbedingten Langzeitfolgen auf die Kohortenmortalität [Sex differences in mortality in West and East Germany with particular consideration of war-related long-term consequences on cohort mortality]. In: Cassens I, Luy M, Scholz RD, editors. Die Bevölkerung in Ostund Westdeutschland: Demografische, gesellschaftliche und wirtschaftliche Entwicklungen seit der Wende. Wiesbaden: VSVerlag für Sozialwissenschaften; 2009. p. 169-98.

20 Saha MV, Davis RE, Hondula DM. Mortality displacement as a function of heat event strength in 7 US cities. Am J Epidemiol. 2014 Feb;179(4):467-74

21 Toulemon L, Barbieri M. The mortality impact of the August 2003 heat wave in France: investigating the 'harvesting' effect and other long-term consequences. Popul Stud (Camb). 2008 Mar;62(1):39-53.

22 Armstrong B, Bell ML, de Sousa Zanotti Stagliorio Coelho M, Leon Guo YL, Guo Y, Goodman P, et al. Longer-term impact of high and low temperature on mortality: an international study to clarify length of mortality displacement. Environ Health Perspect. 2017 Oct;125(10):107009.

23 Feinstein CA. Seasonality of deaths in the US by age and cause. Demogr Res. 2002;6:47188.

24 Huynen MM, Martens P, Schram D, Weijenberg MP, Kunst AE. The impact of heat waves and cold spells on mortality rates in the Dutch population. Environ Health Perspect. 2001 May;109(5):463-70.

25 Stafoggia M, Forastiere F, Michelozzi P, Perucci CA. Summer temperature-related mortality: effect modification by previous winter mortality. Epidemiology. 2009 Jul;20(4):57583.

26 Rocklöv J, Forsberg B, Meister K. Winter mortality modifies the heat-mortality association the following summer. Eur Respir J. 2009 Feb;33(2):245-51.

27 Bongaarts J, Feeney G. How long do we live? Popul Dev Rev. 2002;28(1):13-29.

28 Bongaarts J, Feeney G. When is a tempo effect a tempo distortion? Genus. 2010;66(2):1-15.
29 Luy M, Wegner C. Conventional versus tempo-adjusted life expectancy - which is the more appropriate measure for period mortality? Genus. 2009;65(2):1-28

30 Luy M. Tempo effects and their relevance in demographic analysis. Comp Pop Stud/Z Bevölkerungswiss. 2010;35:415-46.

31 Luy M. Mortality tempo-adjustment: theoretical considerations and an empirical application. In: Barbi E, Bongaarts J, Vaupel JW, editors. How long do we live? Demographic models and reflections on tempo effects. Leipzig: Springer; 2008. pp. 203-33.

32 Luy M. Mortality tempo-adjustment: an empirical application. Demogr Res. 2006;15: 561-90.

33 Peters F, Nusselder WJ, Mackenbach JP. Tempo effects may distort the interpretation of trends in life expectancy. J Clin Epidemiol. 2014 May;67(5):596-600.

34 Manzoli L, Gabutti G, Siliquini R, Flacco ME, Villari P, Ricciardi W. Association between vaccination coverage decline and influenza incidence rise among Italian elderly. Eur J Public Health. 2018 Aug;28(4):740-2.

35 Hiam L, Dorling D, Harrison D, McKee M. Why has mortality in England and Wales been increasing? An iterative demographic analysis. J R Soc Med. 2017 Apr;110(4):153-62.

36 Dowell D, Arias E, Kochanek K, Anderson R, Guy GP Jr, Losby JL, et al. Contribution of opioid-involved poisoning to the change in life expectancy in the United States, 20002015. JAMA. 2017 Sep;318(11):1065-7.

37 Ho JY, Hendi AS. Recent trends in life expectancy across high income countries: retrospective observational study. BMJ. 2018 Aug; 362:k2562.

38 Avendano M, Glymour MM, Banks J, Mackenbach JP. Health disadvantage in US adults aged 50 to 74 years: a comparison of the health of rich and poor Americans with that of Europeans. Am J Public Health. 2009 Mar;99(3): 540-8.

39 Mølbak K, Espenhain L, Nielsen J, Tersago K, Bossuyt N, Denissov G, et al. Excess mortality among the elderly in European countries, December 2014 to February 2015. Euro Surveill. 2015 Mar;20(11):21065.

40 Raleigh VS. Trends in life expectancy in EU and other OECD countries: Why are improvements slowing? Paris: OECD Publishing; 2019.

41 Urban A, Hanzlíková H, Kyselý J, Plavcová E. Impacts of the 2015 heat waves on mortality in the Czech Republic-a comparison with previous heat waves. Int J Environ Res Public Health. 2017 Dec;14(12):1562.

42 Vicedo-Cabrera AM, Ragettli MS, Schindler C, Röösli M. Excess mortality during the warm summer of 2015 in Switzerland. Swiss Med Wkly. 2016 Dec;146:w14379.

43 Cardona C, Bishai D. The slowing pace of life expectancy gains since 1950. BMC Public Health. 2018 Jan;18(1):151. 
44 Raleigh VS. Stalling life expectancy in the UK. BMJ. 2018 Sep;362:k4050.

45 Euromomo: Pooled analyses of all-cause mortality indicates low excess mortality in Europe in the winter of 2013/14, in particular amongst the elderly. 2014. Available from: http://www. euromomo.eu/methods/pdf/pooled_analyses_winter_2013_14.pdf

46 Lytras T, Pantavou K, Mouratidou E, Tsiodras S. Mortality attributable to seasonal influenza in Greece, 2013 to 2017: variation by type/subtype and age, and a possible harvesting effect. Euro Surveill. 2019 Apr;24(14): 1800118.
47 Euromomo: Excess mortality in Europe in the winter season 2014/15, in particular amongst the elderly. 2015. Available from: http://www. euromomo.eu/methods/pdf/winter_season summary_2015.pdf

48 Nielsen J, Krause TG, Mølbak K. Influenza-associated mortality determined from allcause mortality, Denmark 2010/11-2016/17: the FluMOMO model. Influenza Other Respir Viruses. 2018 Apr;12(5):591-604.

49 Bongaarts J, Feeney G. The quantum and tempo of life-cycle events. Vienna Yearb Popul Res. 2006;4:115-51.

50 Sardon JP. A period measure of mortality. The example of France. Popul Engl Selection. 1994;6:131-50.

51 Guillot M. Tempo effects in mortality: an appraisal. Demogr Res. 2006;14:1-26.
52 Human Mortality Database. University of California, Berkeley (USA), and Max Planck Institute for Demographic Research (Germany). 2019 [cited 2019 Feb 4]. Available from: www.mortality.org or www.humanmortality. de

53 Bongaarts J. Five period measures of longevity. Demogr Res. 2005;13:547-58.

54 Bongaarts J, Feeney G. Estimating mean lifetime. Proc Natl Acad Sci USA. 2003 Nov: 100(23):13127-33.

55 Sobotka T, Lutz W. Misleading policy messages derived from the period TFR: should we stop using it? Comp Pop Stud/Z Bevölkerungswiss. 2010;35:637-64. 